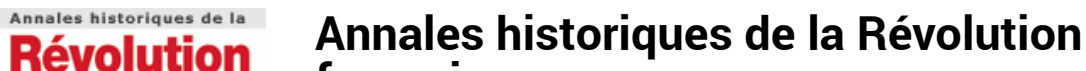

française française

342 | octobre-décembre 2005

Les lles britanniques et la Révolution française

\section{Dumouriez héros et proscrit}

\section{Annie Crépin}

\section{OpenEdition}

\section{Journals}

Édition électronique

URL : https://journals.openedition.org/ahrf/1963

DOI : 10.4000/ahrf.1963

ISSN : 1952-403X

Éditeur :

Armand Colin, Société des études robespierristes

Édition imprimée

Date de publication : 1 décembre 2005

Pagination : 257-260

ISSN : 0003-4436

\section{Référence électronique}

Annie Crépin, «Dumouriez héros et proscrit ». Annales historiques de la Révolution française [En ligne], 342 | octobre-décembre 2005, mis en ligne le 05 avril 2006, consulté le 23 avril 2022. URL : http:// journals.openedition.org/ahrf/1963; DOI : https://doi.org/10.4000/ahrf.1963

Ce document a été généré automatiquement le 23 avril 2022.

Tous droits réservés 


\title{
Dumouriez héros et proscrit
}

\author{
Annie Crépin
}

\section{RÉFÉRENCE}

Jean-Pierre BOIS, Dumouriez héros et proscrit, Paris, Perrin, 2005, 484 p., ISBN

2-262-02058-2 24, $50 €$

1 C'est un portrait nuancé que donne Jean-Pierre Bois dans cet ouvrage où il met en lumière des aspects de l'action d'un personnage controversé, méconnus à cause de son passé d'aventurier ou effacés par sa trahison de 1793. Il a échoué là où Bonaparte a réussi ; mais est-ce une simple question de malchance liée aux circonstances? Quand bien même eût-il réussi, avait-il assez d'envergure pour tenir le rôle que joua Bonaparte? La lecture de ce livre précis et argumenté, qui se garde d'accabler Dumouriez, autorise une réponse négative. L'intérêt de l'ouvrage est ailleurs. S'intitulant Héros et proscrit, il aurait pu être sous-titré: le guerrier et l'homme de plume. L'écrivain militaire et politique se montre maintes fois pénétrant et prémonitoire, sans toutefois atteindre la hauteur de vue des philosophes militaires dont son ami Guibert. L'homme de guerre donne sa pleine mesure lors d'une période charnière de l'histoire militaire.

2 Les lignes directrices de l'œuvre sont données par les portraits croisés que La Fayette et Dumouriez, entre lesquels une comparaison s'impose, tracent l'un de l'autre. Le premier décrit ainsi le second en 1792 : « Militaire politique et intrigant, indifférent aux partis et aux opinions, étourdi, intéressé, inconséquent, ambitieux, mais homme d'esprit, brave, fécond en ressources et doué de grands talents militaires » (p. 182). Mais ce que Dumouriez dit de La Fayette en 1794 pourrait tout aussi bien s'appliquer à lui : « La Fayette [...] avait de l'esprit et des connaissances, mais il manquait de ce génie qui entraîne les hommes, et quelle que fût son ambition, la nature l'avait condamné à la médiocrité » (p. 207).

3 L'ouvrage est structuré en onze chapitres et une conclusion qui se veut le bilan d'une vie. Les trois premiers chapitres retracent les origines familiales et la formation 
intellectuelle du général et exposent sobrement les épisodes de sa vie privée qu'une de ses descendantes, Isabelle Henry, avait entrepris de raconter dans Dumouriez, général de la Révolution (1739-1823), en 2002. Nous avions critiqué dans ces colonnes ( $\mathrm{n}^{\circ} 333$ des A.H.R.F.) cet ouvrage intéressant par son pari de reconstitution, quelque peu romanesque cependant, et par sa présentation psychologique de l'homme, mais discutable par ses approximations sur le contexte historique dans lequel il avait vécu. Rien de tel ici où l'historien, après avoir brossé le tableau d'une famille de la petite noblesse qui, après des méandres inattendus dans le monde du théâtre et dans celui de l'entreprise (les pompes à incendie), redécouvre les chemins plus classiques de l'ascension sociale dans le monde de l'Ancien Régime. Mais elle ne permet pas à ces petits nobles militaires de monter bien haut. Remarquons au passage que Dumouriez a le même profil social que Guibert auquel il fut lié, que Dubois-Crancé qu'il « exécute » en une ligne dans un de ses écrits, voire de Bonaparte. Remarquons aussi que, s'il fait preuve d'ambition, très vite ses talents se heurtent à une barrière difficilement franchissable. Il entre dans la carrière militaire au moment de la guerre de Sept Ans. Il écrit déjà, sans s'élever encore à la réflexion théorique. Après la guerre, il complète sa formation par des voyages au cours desquels il fait preuve de cet esprit aventureux qui le transforme en aventurier aux yeux de certains, ce qui le desservira aux yeux de la postérité, alors que lui-même a été quelque peu victime de calculs qui le dépassaient, quand il est devenu un agent de la diplomatie officieuse et un membre du Secret du Roi, en Italie, en Espagne, au Portugal, en Corse où il participe à la conquête, en Pologne, en Allemagne où il essaie d'assurer la liaison avec la Suède. En fait, même s'il fait preuve d'une activité brouillonne et s'il prend des initiatives hasardeuses, mais non dénuées de sagacité, il n'est qu'un pion aux yeux du gouvernement et parfois le jouet des rivalités entre les puissants qui l'emploient. Cela lui vaut bien des déboires dont l'embastillement mais cela révèle, par la nécessité d'écrire des rapports, «l'homme de plume utile» qu'il sera souvent (p. 50). Jean-Pierre Bois fait remarquer qu'il est dommage que les maréchaux de Napoléon n'aient pas lu ce qu'il écrivait sur le Portugal! D'une façon générale, le grand intérêt de cet ouvrage est de donner une analyse très précise des écrits même mineurs qui nous sont parvenus de Dumouriez et de les replacer dans le débat militaire du temps dans lequel, peut-être stimulé par Guibert qu'il a connu en Corse, et comme lui fasciné par la Prusse, il s'inscrit.

4 Le quatrième chapitre consacré à la période 1775-1789 campe Dumouriez la quarantaine venue, libéré et peut être assagi, marié avec sa cousine et amour de jeunesse, qu'il délaisse sitôt épousée, appelé à devenir une sorte de notable éclairé de province spécialiste des questions internationales et militaires, mais sans véritable réputation. On retrouve la barrière sociale de l'Ancien Régime finissant qui le réduit à végéter dans une position relativement terne. En 1778, il devient commandant de Cherbourg, en fait commandant des troupes de terre qui sont dans la ville. Il se donne tout entier à sa nouvelle tâche qui aurait pu être la grande œuvre de sa vie, encore que l'auteur montre que la transformation de Cherbourg en grand port de guerre est loin de tout devoir à Dumouriez, contrairement à ce qu'il a prétendu dans son désir d'apparaître comme le "Vauban des côtes ». Il accueille Louis XVI en 1786 et est nommé maréchal de camp après le voyage du roi, dans une sorte de récompense tardive.

5 Dumouriez a 50 ans quand éclate la Révolution. Le rôle qu'il y joue est évoqué dans cinq chapitres qui représentent presque la moitié de l'ouvrage. Initialement, Dumouriez reste au second plan, même quand il rétablit l'ordre avec succès dans le Cotentin et en 
Vendée. Il confirme ses opinions de monarchiste constitutionnel et se montre en province homme d'ordre favorable à une révolution modérée. En même temps, il continue à écrire sur les questions de politique internationale. Le 10 mars 1792, il est nommé aux Affaires étrangères, bien qu'il ne compte pas vraiment parmi les Girondins tout en s'étant fait beaucoup d'amis parmi eux car il est toujours homme d'entregent. Le 20 avril, il est à la gauche du roi qui lit le rapport dont il est l'auteur et qui conduit à la déclaration de guerre. Jean-Pierre Bois souligne qu'il est à l'apogée de sa carrière et regrette que les historiens aient passé sous silence le rôle personnel de Dumouriez qu'il estime alors primordial dans un moment déterminant pour l'avenir de la Révolution. Mais s'agit-il du premier rôle ou n'est-il qu'aux premières loges?

6 En fait la grande heure de Dumouriez sonne à l'automne 1792. Le 16 juin, il a démissionné du Ministère de la Guerre qu'il a occupé brièvement. Commandant en chef de l'armée du Nord, le 18 août, il " prend l'épée » et entre sur le terrain, son vrai terrain qu'il n'aurait jamais dû quitter selon son biographe. Il montre le meilleur de lui-même à Valmy sur lequel l'auteur a de très belles pages dans lequelles il réussit encore à écrire $\mathrm{du}$ nouveau. L'historien du fait militaire qu'est Jean-Pierre Bois ne pouvait pas ne pas montrer que, si Valmy fut une canonnade, elle ne fut pas une canonnade mineure d'autant que l'artillerie joue un rôle nouveau et qu'elle est la première bataille qui témoigne de la rupture historique formidable, aussi bien tactique que stratégique, qui survient dans l'art de la guerre. Et surtout, il redonne à Dumouriez une place que son action politique ultérieure et même son passé avaient occultée. C'est en ce sens qu'on peut parler de réhabilitation du personnage, alors que l'auteur se montre ensuite sévère sur l'action politique de 1793 et encore plus sur celle des années suivantes. Mais à Valmy, Dumouriez est le premier grand vainqueur des batailles livrées par la France révolutionnaire. Il a compris la révolution de l'art de la guerre à laquelle cependant, ajoute l'historien, il a assisté plus que contribué (p. 245). Jemmapes confirme à la fois les caractères de la guerre révolutionnaire et que Dumouriez est le plus grand homme de guerre avant Bonaparte, le premier des grands généraux de la République issus des officiers de l'Ancien Régime, même si Jean-Pierre Bois ne cache pas les critiques de Jomini.

7 La rupture avec la Convention est analysée avec rigueur dans toutes ses étapes par l'auteur qui montre comment la dérive se transforme en tentative de coup d'État mais non de conspiration, car Dumouriez ne fait aucun mystère de ses intentions, au contraire. La rupture n'a pas lieu uniquement à propos du sort de la Belgique: d'ailleurs, si on suit l'historien sur le rôle de Dumouriez dans « la guerre de l'an I », on le suit moins quand il veut dédouaner Dumouriez de l'intention de mettre la Belgique en coupe réglée en estimant qu'il voulait la libérer ; vraisemblablement, mais il n'était pas le seul, il poursuivait en toute sincérité les deux desseins à la fois. Il franchit donc le Rubicon sur le plan politique. L'historien s'essaie à un parallèle avec Bonaparte en Brumaire que Dumouriez a esquissé lui-même. Dumouriez, un Bonaparte malchanceux ou desservi par les circonstances? L'historien a des pages très nuancées dans lesquelles il reconnaît que Bonaparte vainqueur ne traite pas avec les ennemis et qu'un coup d'État peut être fait avec une armée victorieuse, mais non avec une armée battue. Or, Dumouriez est le vaincu de Neerwinden. Surtout, ses soldats qui auraient suivi le rebelle ne suivent pas le traître. L'auteur estime que son erreur majeure fut de ne pas subordonner son destin à la cause qu'il servait, c'est-à-dire au destin de la nation, mais de rechercher dans les événements la réalisation de ses propres ambitions. Nous 
ajouterions que l'homme politique ne fut pas à la hauteur de l'homme de guerre et qu'il n'avait pas la carrure de ses ambitions.

Dès lors, il retombe au second plan ou pire, car c'est après sa rupture qu'on peut parler de la trahison dans laquelle il s'enfonce de plus en plus à partir du moment où il passe au service de l'Angleterre, après avoir tenté au préalable de passer à celui de l'Autriche. C'est à la plus triste période de sa vie qu'est consacrée la fin du livre. Pourtant l'essentiel de la vie du proscrit qui erra longtemps avant de pouvoir se fixer en Angleterre devient l'écriture, il a même une extraordinaire activité de plume vouée, en grande partie, mais pas seulement, à se justifier. Ces écrits qu'il poursuivra jusqu'à sa mort survenue en 1823 ne méritent pas, selon l'auteur, l'oubli dans lequel ils sont tombés. Ce livre qui est beaucoup plus qu'une biographie et n'est pas pour autant un plaidoyer simpliste se termine par une très utile chronologie, établie chapitre par chapitre. 